its fangs into itself, when confined in a gallon jar containing water, which was inverted at intervals in order to drown it, is open to question as to its conclusion that it was a case of "deliberate suicide," for the following reasons :-

(I) That it was after " the snake ceased any attempt to rise to the surface of the water in the jar," that the blow was struck. The snake then being wholly beneath the water, would die from drowning, and not from the self-inflicted wounds caused by its poisoned fangs.

(2) That it has been proved by experiment by Dr. Weir Mitchell that the venom of the rattlesnake is of no effect upon itself, when introduced into any wound in its body. I speak from memory of an article which appeared in the Atlantic Monthly some few years ago. That self-insertion of the poison would make any difference is not likely.

Drowning (by the act of others) and not self-poisoning (or suicide) I take to be the cause of death in the case described.

Halifax, August 15 . W. H. WOOD.

\section{Numerous Insects Washed up by the Sea.}

THE phenomenon referred to under the above heading in your issue of August I 7 may be in part accounted for by the fact that on August 7, at many spots in the neighbourhood of Godalming (S. W. Surrey), the air was thick for several hours with swarms of winged ants. The direction of the wind was from the north-west, force moderate. Assuming the like to have taken place at other places, it is quite possible that large numbers of ants may have been carried out to sea and drowned from this region of Surrey and Hampshire.

Hunstanton, August 19.

Oswald H. Latter.

\section{THE FUNGUS GARDENS OF CERTAIN SOUTH AMERICAN ANTS.}

$\mathrm{NE}$ of the most interesting papers that has appeared during the present year, whether considered from the point of view of general biology or of mycology, is that which has recently been published by Herr Alfred Möller, nephew of Dr. Fritz Müller. ${ }^{1}$ The work was carried out at Blumenau during the years $1890-92$, and presents a clear and thorough investigation into the habits of the leaf-cutting ants and their remarkable custom of cultivating and feeding upon certain fungi. The work is introduced by a quotation from Thos. Belt's "Naturalist in Nicaragua," where the author, speaking of the leaf-cutting ants, states: "I believe.... that they are in reality mushroom growers and eaters." This statement Möller fully proves in the work before us. The first portion, forming the bulk of the work, is given up to the consideration of the fungu; gardens of the leafcutting ants, and is divided into ten sections.

I. The species of the leaf-cutting ants and their activity outside of the nest-Belt's description ${ }^{2}$ of the Nicaraguan ants is quoted, and the differences between them and those of Blumenau are pointed out. The chief point of difference is that the latter form very narrow streets, travelling only in single file, and that their nests occur both in the forest and in the open. The commonest species is Atta (Acromyrmex) discigera, Mayr, whose workers are never more than $6.5 \mathrm{~mm}$. long. Almost as common is $A$. hystrix, Latr., whose workers reach a length of $9 \mathrm{~mm}$. Rarer than these are $A$. coronata, Fabr., and a doubtful form, which Möller terms Atta $I V$.

A minute description is given of a street of $A$. discigera, which was 26 metres long and about $\mathrm{I} \cdot 5 \mathrm{~cm}$. wide and high, roofed in in parts wherever possible. It led to a number of small Cupheas, whose leaves the ants were cutting. In the street could be seen a procession of loaded ants going towards the nest, and others emptyhanded, going in the opposite direction. Some of the large workers run up and down the road unloaded, and

1 "Die Pilzgärten einiger südamerikanischer Ameisen." Heft 6 of Schimper's " B stanische Mittheilungen aus den Tropen." (Jena: G. Fischer, 1893.) act as road-menders if any accident happens to a part of the track. Other very small workers, which do not cut leaves, may also be seen carried upon the backs or even upon the loads of the actual leaf-cutters. An ant carrying a peculiarly shaped piece of leaf was watched from end to end of the track, and travelled the $26 \mathrm{~m}$. in 70 minutes. The load was twice as heavy as itself.

The other species of the Atta have very similar streets. A. hystrix appears to work only at night.

The jaws of the ants are very strong, with serrated edges, and clash together laterally. The ant begins at the edge of a leaf, and cuts out a piece in about five minutes, revolving on one of its hind legs as a centre. When the piece is almost freed, the ant goes on to the main portion of the leaf, cuts through the last piece uniting it with the severed portion, drags up the latter, balances it on edge between its forelegs, and then, grasping it with its jaws, lifts it up above its head, so that the centre of gravity of the load is above the ant itself. It then marches off, down the stem, to the base, over the ground to the end of the street, and along this to the nest, travelling at a very uniform speed, and never letting go its load. The weight thus carried was found, on an average, to be twice that of the ant; but many were found carrying heavier loads, even as much as ten times their own weight! A street of $A$. coronata was watched for fifteen minutes, during which time $2 \mathrm{I} 7$ ants passed, carrying 3 grammes of leaves.

2. The Niests of the Ants, and the Fungus Gardens.The nests of $A$. hystrix and $A$. discigera are usually below the surface of the soil, but covered, wherever necessary, with a thick mass of withered pieces of leaves and twigs, \&c. They may be as much as $I^{\frac{1}{2}}$ metres in diameter. In the nests of all four species there is found, filling up the interior, a curious grey spongy mass, full of chambers, like a coarse sponge, in which the ants may be seen running about, and in which, here and there, occur eggs, larvæ, and pupæ. This is the fungus garden, termed by Belt "ant-food." It is separated from the roof and lateral walls of the nest by a clear space. The walls and roof are much thicker in winter than in summer; one nest examined had a roof $25 \mathrm{~cm}$. thick and wall $40 \mathrm{~cm}$. Photographs are given in the original paper, showing the appearance of the mushroom garden.

3. Investigation of the Gardens. The Kohl-rabi clumps.-The garden consists of two parts, differently coloured, but not very sharply marked off from one another. The older part is yellowish-red in colour; the newly-built portions, forming the surface of the garden, are of a blue-black colour. It is this part which is of the greater importance to the ants.

The garden is found, on examination, to consist of an immense conglomeration of small round particles of not more than $5 \mathrm{~mm}$. in diameter, of a dark green colour when quite fresh, then blue-black, and finally yellowishred. They are penetrated by, and enveloped in, white fungus hyphæ, which hold the particles together. These hyphæe are similar throughout the nest.

Strewn thickly upon the surface of the garden are seen round white bodies about $25 \mathrm{~mm}$. in diameter; they always occur in the nests, except in the very young portion of the gardens. They consist of aggregations of peculiar swollen hyphæ, and are termed by Möller the "Kohl-rabi clumps." The hyphæ swell out at the ends into large spherical thickenings, about $10-24 \mu$ in diameter (the ordinary hyphæ are $5-8 \mu$ thick), filled with richly vacuolated protoplasm like the ordinary hyphæ. These clumps of "Kohl-rabi" are only found on the surface of the garden, and form the principal food of the ants. A microscopic examination of the particles of which the garden is composed shows that they contain remains of leaves; bits of epidermis, stomata, spiral vessels, \&c., occur in them.

4. The Importance of the Garden to the Ants. -If a nest be broken into and the garden scattered the ants collect 
it as quickly as possible, especially the younger parts, taking as much trouble over it as over the larvæ. They also cover it up again as soon as possible to protect it from the light. A nest, I metre $\times 50 \mathrm{~cm}$. was opened, and in twenty-four hours the ants had put on a new roof $10 \mathrm{~cm}$. deep. They also carry the nest with them upon their migrations

5. The Use of the Garden: its Construction and its Tendance observed in Captivity.-Some ants' nests were placed under a bell jar and supplied with leaves; they made no use of them and presently died. If they were supplied with a piece of "garden," they rebuilt it and covered it so far as they could. It was seen to shrink from day to day, the ants bringing out the old pieces and adding them to the wall ; finally it was exhausted and the ants died. Others were starved for five days, and then supplied with a bit of garden; they at once began to eat the Kohl-rabi clumps. It was found by this means that each species of Atta will eat the Kohl-rabi of the other three as well as its own. Finally, by supplying the ants with bits of garden, a damp sandy floor, and fresh leaves, they were induced to build in captivity. The dish in which they worked was covered by a glass lid, and when this was covered with a dark cloth or otherwise kept dark, the ants built under it without covering the garden. In this way the whole process was observed. An ant bringing in a piece of leaf proceeds to cut it into halves, repeating the process till it has got a very small piece left, which it holds between its fore feet and turns round, crushing it in its jaws until the whole is reduced to a round ball of pulp about ' $25 \mathrm{~mm}$. thick. This it then takes and adds to the garden. So well is the kneading performed that no single cell remains uninjured, and it was observed that the hyphæ of the fungus grew through and round one of these particles within a few hours. Belt supposed that this process was performed by the small workers abovementioned, but it is not so, as we have just seen. The small workers perform the function of weeding the garden, and this is so well done that a portion of it removed and grown in a nutrient solution gives a perfectly pure culture, not even containing bacteria !

6. Development of the Fungus after removal of the ants; the conidia, "pearl-hypha," and strand-swellings. Result of the artificial culture of the Fungus.-If a portion of garden be left to itself in darkness, the ants having been removed, aerial-hyphæ develop in a thick mass several centirnetres high, with many anastomoses; the Kohl-rabi clumps are used up in the process, apparently supplying material for it. The formation of conidia now takes place all over the mass. From a hypha there buds out a lateral projection, which bears branches arranged roughly in whorls: upon these are again borne whorls of small clubshaped branches, from whose ends are abstricted rows of conidia, whose diameter is $2 \mu$; there are, as a rule, not more than ten in a row. Occasionally the formation of the strings of conidia occurs not only on the final branches, but also on those of the preceding order. After the conidia are formed the mass collapses (about the fifth day).

About the third day a careful search reveals among the ordinary hyphæ a few which are covered, as with rows of pearls, with small spherical lateral protuberances. These "pearl-hyphæ" arise from the ordinary ones. The cavity of the "pearl" is in direct communication with that of the hypha itself, and contains protoplasm. In connection with these there occurs a second type of conidia formation, distinguished by Möller as the "weak" formation. There is no preliminary branching, the conidia being abstricted from the ends of the pearl hyphæ, or plain hyphæ in connection with them. The end of the hypha swells up and bears the conidiophores. The chains generally consist of at least twenty conidia.

Still a third form of hypha is to be found. Sooner or later there are observed on the garden thick white strands, which on examination are found to consist of hyphæ, which look like rows of beads, or yeast-chains, and are much bent, branched, and twisted. From these there arise pearl hyphæ, or we may find pearls upon these hyphæ themselves. These peculiar hyphæ arise first of all as "pearls" on ordinary hyphæ, and then a process of budding goes on, just like that which gives rise to yeast chains. The "pearls" might be looked upon as homologous with these lateral swellings of hyphæ, but there is also another view, that they represent rudimentary conidiophores. It has been seen above that the conidiophores in the "strong" conidia formation are not always confined to the ends of the hyphr, but may at times appear further back, and it is suggested that originally they were borne anywhere upon the hyphæ, and subsequently restricted to the tips, the "pearls" then representing rudimentary conidiophores. The "pearl" hyphæ and weak conidia formation are usually found in connection with these swollen strands, and on one or two occasions a connection was found with the strong conidia formation.

When a few ants were left with a large piece of garden, they did their utmost to prevent the formation of these aerial hyphæ, \&c., biting them off as they appeared, but gradually the fungus gained the upper hand of them. Proceeding now to the results of culture in nutrient solutions, the strong conidia germinate and give rise to hyphæ which ultimately bear strong conidia again. Never did the "weak" form appear, but very often from the main hypha there were given off lateral branches, some of which developed into rows of beads, like the hyphæ described above, and others swelled up at the ends just like the Kohl-rabi. The cultures being pure, these formations could not be pathological, produced by bacteria, as is sometimes the case.

Similarly the weak conidia gave rise only to conidia like themselves. Pearl-hyphæ were occasionally formed, and rarely the peculiar hyphæ like rows of beads.

When one of these forms was grown in one culture drop, and bent over into another drop, in which the other form was, the two anastomosed freely, showing that they belonged to the same plant.

When a portion of Kohl-rabi is grown in the solution it gives rise to ordinary hyphæ, which ultimately produce a new crop of Kohl-rabi. On one occasion it gave rise to pearl-hyphæ and weak conidia.

To sum up, the fungus has two conidia forms, which develop upon the garden in the absence of the ants. The mycelium shows a strongly marked tendency to the formation of swellings and protuberances, which appear in a different form, more or less distinctly marked. One of these, which has probably reached its present form under the cultivation and selection of the ants, is the Kohl-rabi. 7. Discovery of the Highest Fructification of the Fungus. - It being evident that the fungus was either a Basidiomycete or Ascomycete, attempts were made to obtain its principal fructification by cultivation, but in vain. A fortunate discovery, however, was made of a nest which had a huge red Amanita-like fungus growing out of it. This was found to belong to the genus Rozites, and the species was named $R$. gongylophora. The development of the basidia, \&c., is given in detail, but need not be gone into here. Cultivation of the spores showed that this was indeed the fructification of the Kohl-rabiforming fungus.

ro. Plants attacked by Leaf-cutting Ants.-These were found to be very numerous, and no rule could be formulated as to the operations of the ants. On one day they would strip one plant and the next day leave it untouched, or vice versá. An interesting case was observed in the cold weather. An army of leaf-cutters was found stripping a Cecropia, though the latter was inhabited at the time by its protecting ants! The latter appeared to be too numbed by the cold to go out and fight. 
THE GaRdens OF THE HAIRY ANTS.

While working at the preceding it was discovered that somewhat similar fungus gardens cccur in the nests of Apterostigma. Four species were studied. All have the same fungus, belonging apparently, however, to a different genus from Rozites. These hairy ants live in decaying wood and have small gardens $4-8 \mathrm{~cm}$. in diameter, built of bits of wood-fibre, beetle-dung, \&c. The chief point of interest is that though all have the same fungus yet all have not cultivated and selected the Kohlrabi to the same degree. A. Wasmanni, Forel, has a well-developed type with large spherical swellings on the ends of the hyphæ. The others have Kohl-rabi of a much lower type, the hyphæ being only slightly swollen into a club shape, and they are not aggregated into regular groups.

It was, as usual, found impossible to obtain by artificial culture the highest fructification of the fungus, so its systematic position is still undetermined.

\section{THE Gardens OF CYPHOMYRMEX.}

This genus of ants is closely related to the two preceding, and the two species examined ( $C$. auritus, Mayr, and C. strigatus, Mayr) are also fungus-growers. Both form nests like those of Apterostigma, and use similar material in the garden. The two species have the same fungus, but $C$. strigatus obtains far finer Kohl-rabi than $C$. auritus, just as we have seen to be the case with the species of Apterostigma. It is thus pretty evident that the large size of the best Kohl-rabi must be due to selection and cultivation on the part of the ants.

The concluding pages of the work are taken up by a discussion of the mycological results of these investiga tions, for which reference must be made to the original. The work is illustrated by beautiful plates, and forms as a whole one of the most fascinating contributions to botanical literature that have been made for many years. JOHN C. WILLIS.

\section{A FEW REMARKS ON INSECT PREVA-}

LENCE DURING THE SUMMER OF I893.

$\mathrm{WE}$ are hearing a great deal just now of unusual amount of insect presence, and there appears no reason to doubt that such is very much the case, although for scientific use we need much more of reliable report than we possess as to what kinds of insects are noticeably more present than in seasons of ordinary meteorological conditions, and also we need observations as to what kinds may be unusually absent.

So far as my own acquaintance with the subject (which is mainly in reference to amount of presence of crop insects) allows me to judge, these unusually large amounts where they oscur-for the superabundance does not affect all kinds-may be attributed to weather influence acting either directly on the development of the insects themselves, or so affecting the state of their crop-food-plants as to induce the conditions which we know well by the agricultural experience of many years are favourable to establishment of infestation.

The important preliminary as to there having been really such a definite deficiency in rainfall as to amount to what may be called "a drought" over England and Wales, we have stated shortly in the Monthly Meteorological Masazine, of Mr. G. J. Symons, F.R.S., No. cccxxxi, p. 98, as follows :--"Assuming that the twentyfour stations fairly represent England and Wales, we find that in March the rainfall was only one-third of the average, in April one-sixth, in May three-quarters, and in June two thirds." Mr. Symons further points out that "this, of course, is taking the country as a whole ; at many individual stations the results would be much more striking, e.g. at Bodmin in the three months " (March to May) "only one fifth of the average fell."

Amongst insect attacks especially subject to increase by stunting of growth, or over-maturation of sap of their food plants, are those of the Aphides or Plant Lice, which have been- so far as my own contributors' reports show-unusually early and prevalent this year. They were forwarded on mangolds from Devonshire almost as soon as there could be said to be good accommodation for attack on the leafage, and turnips and cabbage leafage, damson early in the season, and larch later on the borders of England and Scotland, were some of the tree and food plant habitats which were exceptionally afflicted. These prevalences agree with the rule of Aphis life laid down by Mr. G. B. Buckton, F.R.S., our great authority on Aphis life. In drawing attention to the abnormally rapid increase of Aphides under some circumstances, he accounts for it by maturity (i.e. power of reproduction) taking place earlier in the life stage where from various causes inducing want of supply of nutriment, structural changes occur consequently on these in the larvæ of the Aphides subsequently born. (See "Brit. Aphides," by G. B. Buckton, F.R S., vol. i. p. 72).

Besides the above reasons for increase, we have also the negative reason of absence of destruction by good drenching rains to wash off and often to drown the enemy. One of my correspondents wrote me that he had been doing this or that, but the best help was the welcome rain.

The above may be taken as a type of one way in which weather influence acts ; in the case of wasps, which popularly represent much of insect presence to the world at large, we have another set of influences.

Our recent drought began in March. In many years we have the most variable weather at this season, and the queen wasps, the foundresses of the coming colonies, being tempted from their winter localities of hybernation by a day or two's warmth, are caught, it may be, by heavy rain, or by snow, or by frost, and perish. This year weather was more favourable to them, and we had not the drenching rains which in an ordinary year put an end to many an embryo nest with its few grubs, whether in ground or hedge. The first commencement, formed of a tiny piece of paper, in shape like an umbrella, with beneath it a pendant ending in a club formed of a few cells, each with its egg or young maggot tenant is delicate in the extreme. If the cavity in which it is placed in the ground is flooded, its destruction is certain, or if in storms the foundress cannot return to feed the young family they must perish.

In the case of wasps, probably weather influences, which affect amount of any particular kind of food are as, little troublesome as to any insect. All who at all study their habits are aware that flesh, fish, insects to a large amount, and fruit to utter rapacity of consumption, are constantly utilised by them for their own special support or that of the maggot family. To what extent the adult wasps may feed on other than vegetable matter I cannot say, but dissection and examination of the undigested food in the blind pouch of the food canal of the larval wasp has shown this to consist of remains both of animal and vegetable matter; in the record before me chiefly of insect débris. Their varied kind of food and their wonderful adaptability of instinct in making adverse circumstances suitable for the household needs, make the wasp family when once established, most prolific pests.

The great prevalence of what are called surface caterpillars, that is, the Iarvæ of various kinds of Agrotis at the roots of various kinds of field crops, gives an example of increase of presence of the Lepidoptera, under circumstances favourable to the development of the imago from the chrysalis, and subsequently to the pairing of the moths and successful egg deposit. In wet and chill weather, when the moths hang about torpidly, a certain proportion of them get drenched, so that their wings are of little service ; the larvæ are injured in different ways, or disease induced, much influencing amount of presence.

No. I 243 , VOL. 48 ] 